\title{
Estimation of the relative fertilizing ability of frozen chicken spermatozoa using a heterospermic competition method*
}

\author{
A. Tajima $\dagger$, E. F. Graham and D. M. Hawkins $\ddagger$ \\ Departments of Animal Science and $\ddagger$ Applied Statistics, University of Minnesota, \\ St Paul, Minnesota 55108, USA
}

\begin{abstract}
Summary. Semen was collected from Rhode Island Red and White Leghorn roosters. After adjusting the sperm number from both breeds, half of the semen was frozenthawed in the presence of glycerol. Frozen and unfrozen semen from both breeds was mixed 1:1 with all four possible combinations and inseminated into Rhode Island Red hens. Feather colour of chicks was used to determine which breed fertilized the eggs. Results showed that sperm cells retained $19 \cdot 7 \%[95 \%$ confidence interval $=(12 \cdot 8$, $30 \cdot 4)$ ] of the relative fertilizing ability after freezing. Furthermore, Rhode Island Red spermatozoa had 1.5 times $[95 \%$ confidence interval $=(1 \cdot 1,2 \cdot 0)]$ higher relative fertilizing ability than did White Leghorn spermatozoa. The heterospermic competition assay method is a powerful tool for estimating the relative fertilizing ability of the sperm cells.
\end{abstract}

Keywords: chicken; semen; frozen; fertility; sperm competition

\section{Introduction}

Relative fertilizing ability of the sperm cell in chickens is difficult to estimate primarily because estimation is based on the proportion of physiologically intact cells in an extremely large population of cells. In cattle, fertility is asymptotically approached to the maximum fertility level with an increasing value of certain semen characteristics (Salisbury \& VanDemark, 1961). In chickens, Wishart (1985) reported that only $1.6 \%$ of the frozen sperm cells kept their fertilizing ability. His observation was based on a comparison of fertility when inseminating different numbers of sperm cells. Heterospermic insemination has been used to evaluate the relative fertilizing ability of unfrozen spermatozoa in chickens (Martin et al., 1974; Martin \& Dziuk, 1977), in cattle (Beatty et al., 1969) and in rabbits (Roche et al., 1968; O'Reilly et al., 1972). Heterospermic inseminations are more sensitive for evaluating treatment differences in chicken semen than are homospermic inseminations (Martin \& Dziuk, 1977). Also, heterospermic inseminations are not influenced by total sperm numbers, breed of hen or season but are dependent on the ratio of competing sperm numbers (Martin et al., 1974). The present experiment applied the principle of heterospermic competition to estimate the relative fertilizing ability of frozen chicken spermatozoa.

\section{Materials and Methods}

Semen was collected from at least 10 proven Rhode Island Red (RIR) and White Leghorn (WL) roosters by the method described by Burrows \& Quinn (1937). Care was taken to avoid fecal and urate contamination. For each

*Reprint requests to Dr E. F. Graham.

†Present address: Institute of Agriculture and Forestry, University of Tsukuba, Ibaraki, Japan 305. 
breed, clean semen samples with vigorous swirling movement were pooled and diluted 1 part semen to 3 parts diluent with Minnesota Avian buffer (MnA) (see below for the chemical composition of $\mathrm{MnA}$ buffer) containing $8 \%(\mathrm{v} / \mathrm{v}$ ) final concentration of glycerol. Sperm concentrations were measured for each sample with a spectrophotometer and samples were further adjusted to an equal number of sperm cells per $\mathrm{ml}$. Half of the semen from each breed was frozen. The freezing protocol was as follows. (1) Semen was held for $30 \mathrm{~min}$ at $5^{\circ} \mathrm{C}$ for equilibration. (2) The semen was packaged in $0.25-\mathrm{ml}$ plastic straws and frozen with a programmable freezer at the rate of $-3^{\circ} \mathrm{C} / \mathrm{min}$ until the temperature reached $-45^{\circ} \mathrm{C}$, followed by $-20^{\circ} \mathrm{C} / \mathrm{min}$ from $-45^{\circ} \mathrm{C}$ to $-100^{\circ} \mathrm{C}$. Frozen semen was then plunged into liquid nitrogen and held for $1 \mathrm{~h}$. (3) Straws were thawed in air at $5^{\circ} \mathrm{C}$ for $5 \mathrm{~min}$. An unfrozen portion of semen was held at $5^{\circ} \mathrm{C}$ for approximately $4 \mathrm{~h}$. After the thawing procedure, $2 \mathrm{ml}$ each of frozen (f) and unfrozen (u) semen from WL and RIR birds were mixed 1:1 as follows: Group 1, u-WL + u-RIR; Group 2, f-WL + f-RIR; Group 3, $\mathrm{u}$-WL + f-RIR; Group 4, f-WL + u-RIR. Semen was rediluted by adding unglycerolated chicken buffer at $0.2 \mathrm{ml} / \mathrm{min}$ for the first $10 \mathrm{~min}$ followed by $0.4 \mathrm{ml} / \mathrm{min}$ for the next $10 \mathrm{~min}$. Rediluted semen was then centrifuged at $700 \mathrm{~g}$ for $20 \mathrm{~min}$. After removing the supernatant, semen was resuspended with unglycerolated chicken buffer at a rate of $0.04 \mathrm{ml} / \mathrm{min}$ for the first $10 \mathrm{~min}$ followed by the same volume every $30 \mathrm{sec}$ until the sperm number reached $450 \times 10^{9} / \mathrm{ml}$. After reconstitution, $100 \mu \mathrm{l}$ semen per bird were inseminated intravaginally. RIR hens with good laying records were randomly assigned to 1 of the 4 groups: 5 hens were assigned to Group 1, and 8 hens were assigned to each of the other 3 groups. The hens were inseminated once a week for 4 weeks. All eggs were incubated until hatched. In each treatment group, the number of chicks with white or red feathers were counted. The WL carries a dominant pigment inhibitor gene and so male parent identity can be ascertained in newly hatched chicks. Unhatched fertilized eggs were broken. The feather colour of the chicks of late embryonic death was also included in the data.

The data constitue a $2 \times 2$ factorial design for the factors of feather colour (WL/RIR) and freezing (frozen/ unfrozen) with 4 replicates (eggs from each week). The feather colour of each chick is either WL or RIR, and the probability of each possible result depends on which combination of semen was used. A plausible model would be that these probabilities are proportional to the product of 2 factors, (1) a breed factor reflecting possible differences in the overall fertility of the 2 breeds, and (2) a factor for whether that semen was frozen or unfrozen. Each egg obtained from each treatment group in each week then constitutes a Bernouilli trial. This log linear model is effectively analysed using a logistic model (Bishop et al., 1975; Fienberg, 1980) as follows. Let i denote the treatment group and $\mathrm{j}$ the week. Let $n_{i j}$ be the total number of eggs obtained in this group and week whose feather colour could be determined, $x_{i j}$ the number that were RIR. Then $x_{i j}$ follows a binomial distribution with parameters $n_{i j}$ and $p_{i j}$, with the probability $p_{i j}$ being given by the logistic model:

$$
\log _{\mathrm{e}} \frac{\mathrm{p}_{\mathrm{ij}}}{1-\mathrm{p}_{\mathrm{ij}}}=\beta_{0}+\beta_{1} \mathrm{w}+\beta_{2 j}
$$

where $w=0$ for $i=1,2,1$ for $i=3$ and -1 for $i=4$. The coefficient $\beta_{0}$ measures the relative fertility of the RIR semen compared to the WL, $\beta_{1}$ is the effect of freezing, and $\beta_{2 \mathrm{j}}$ allows for possible systematic differences between the 4 weeks.

This model was fitted using the CATMOD procedure from SAS (1985) for categorical data analysis. This procedure fits linear models to functions of response frequencies using categorical data modelling. CATMOD estimates a probability vector and covariance matrix using the multinominal distribution and uses the maximumlikelihood iterative method to estimate the parameters of log linear response functions. The CATMOD procedure also uses the weighted-least-squares method for testing $\chi^{2}$ goodness of fit for the model and significance of other sources of variance. This procedure is comparable to GLIM 3-77 (NAG, 1986).

The composition of the MnA buffer $(100 \mathrm{ml})$ was: $4 \mathrm{~g}$ Tes ( $N$-Tris(hydroxymethyl) methyl-2-aminoethane sulphonic acid), $4 \mathrm{~g}$ Hepes ( $N$-2-hydroxyethyl-piperazine- $N^{\prime}$-2-ethane sulphonic acid), $3 \mathrm{~g}$ Bes ( $N, N$-bis(2-hydroxyethyl)-2 aminoethane sulphonic acid), $1 \mathrm{~g}$ potassium hydroxide, $10 \mathrm{~g}$ glucose, $0.7 \mathrm{~g}$ sorbitol, $7.0 \mathrm{~g}$ potassium phosphate dibasic, $1.6 \mathrm{~g}$ potassium phosphate monobasic, $0.8 \mathrm{~g}$ sodium phosphate dibasic, $0.5 \mathrm{~g}$ potassium citrate, $0.35 \mathrm{~g}$ magnesium sulphate, $2.1 \mathrm{~g} \mathrm{~L}$-glutamic acid (monopotassium salt), $6.0 \mathrm{~g} \mathrm{~L}$-glutamic acid (monosodium salt), $2.5 \mathrm{~g}$ sodium acetate, and $2 \cdot 1 \mathrm{~g}$ potassium acetate, $\mathrm{pH} 7 \cdot 1$ and osmotic pressure $370 \mathrm{mosmol} / \mathrm{kg}$.

\section{Results}

Weekly results, including number of eggs laid per treatment, number of eggs hatched, and number of RIR hatched are shown in Table 1. The percentage hatch of total eggs for the mixture of $\mathrm{u}-\mathrm{WL}+\mathrm{u}-\mathrm{RIR}$ was $81 \cdot 3$ compared to $44 \cdot 1$ for the mixture of $\mathrm{f}-\mathrm{LW}+\mathrm{f}-\mathrm{RIR}$, reflecting the difference between fresh and frozen semen. However, the mixture of fresh + frozen semen yielded $95.8(\mathrm{u}-\mathrm{WL}+\mathrm{f}-\mathrm{RIR})$ and $73.9(\mathrm{f}-\mathrm{WL}+\mathrm{u}-\mathrm{RIR})$ percentage hatch of total eggs.

The parameter estimates (Table 2 ) show that both the intercept $\left(\beta_{0}\right)$ and indicator $\left(\beta_{1}\right)$ variables were significant $(P<0.01$ and $P<0.001$, respectively). The model exhibited no significant lack of fit, and the week effects were not significant. From the way the indicator variable is defined, an estimate for the indicator variable is interpreted as the effect of freezing on the relative fertilizing 
Table 1. Total number of eggs laid, total number of eggs hatched, and number of RIR chicks

\begin{tabular}{|c|c|c|c|c|c|c|c|c|c|c|c|c|}
\hline \multirow[b]{2}{*}{ Week } & \multicolumn{3}{|c|}{$\begin{array}{c}\text { Group I } \\
(u-W L+u-R I R)\end{array}$} & \multicolumn{3}{|c|}{$\begin{array}{c}\text { Group } 2 \\
\text { (f-WL }+ \text { f-RIR) }\end{array}$} & \multicolumn{3}{|c|}{$\begin{array}{c}\text { Group } 3 \\
(\mathrm{u}-\mathrm{WL}+\mathrm{f}-\mathrm{RIR})\end{array}$} & \multicolumn{3}{|c|}{$\begin{array}{c}\text { Group } 4 \\
(\mathrm{f}-\mathrm{WL}+\mathrm{u}-\mathrm{RIR})\end{array}$} \\
\hline & Eggs & Hatched & RIR & Eggs & Hatched & RIR & Eggs & Hatched & RIR & Eggs & Hatched & RIR \\
\hline 1 & 27 & 23 & 10 & 36 & 20 & 10 & 24 & 20 & 5 & 22 & 15 & 13 \\
\hline 2 & 25 & 24 & 15 & 39 & 20 & 12 & 30 & 30 & 8 & 25 & 20 & 17 \\
\hline 3 & 17 & 14 & 9 & 25 & 12 & 9 & 16 & 16 & 3 & 15 & 13 & 11 \\
\hline 4 & 22 & 13 & 8 & 36 & 8 & 6 & 25 & 25 & 5 & 30 & 20 & 19 \\
\hline Total & 91 & 74 & 42 & 136 & 60 & 37 & 95 & 91 & 21 & 92 & 68 & 60 \\
\hline
\end{tabular}

Abbreviations: $\mathrm{u}=$ unfrozen; $\mathrm{f}=$ frozen; $\mathrm{WL}=$ White Leghorn; $\mathrm{RIR}=$ Rhode Island Red.

Table 2. Maximum likelihood estimates of the parameters

\begin{tabular}{lcc}
\hline Effect & Estimate & $\begin{array}{c}\text { Standard } \\
\text { error }\end{array}$ \\
\hline$\beta_{0}$ (RIR/WL) & $0.405^{* *}$ & 0.143 \\
$\beta_{1}$ (effect of freezing) & $-1.625^{* * *}$ & 0.217 \\
$\beta_{22}$ (Week 2) $\dagger$ & -0.361 & 0.227 \\
$\beta_{23}$ (Week 3) $\dagger$ & 0.061 & 0.217 \\
$\beta_{24}$ (Week 4) $\dagger$ & 0.122 & 0.260 \\
\hline
\end{tabular}

$\dagger$ Each week compared with previous week.

**Significant at $P<0.01$.

*** Significant at $P<0.001$.

Deviance $=7.54$ with 14 degrees of freedom is not significant.

ability of the sperm cells. Deviation of the $y$ intercept from 0 is interpreted as the difference of sperm relative fertilizing ability between RIR and WL.

Relative fertilizing ability of spermatozoa $=\mathrm{e}^{-1.625 \pm 0.217}$

$$
\begin{aligned}
& =0.197[95 \% \text { C.I. }=(0 \cdot 128,0.304)] \text { or }=19.7 \% \\
& \text { and } \\
\text { RIR/WL ratio } & =\mathrm{e}^{0.407 \pm 0.143} \\
& =1.50[95 \% \text { C.I. }=(1 \cdot 13,2.00)]
\end{aligned}
$$

where

$\mathrm{e}=$ base of the natural logarithm.

Therefore, it was concluded that the relative fertilizing ability of the sperm cells was reduced to $19.7 \%$ of the unfrozen spermatozoa and RIR spermatozoa were on the average 1.50 times more fertile than WL spermatozoa in all of the 4 groups tested.

\section{Discussion}

In the present experiment, the relative fertilizing ability of the frozen chicken spermatozoa was estimated to be $19.7 \%$ that of unfrozen sperm cells. This value is over 10 times higher than the 
estimation by Wishart (1985) who reported that only $1.6 \%$ of frozen chicken spermatozoa retained their fertilizing ability. The differences in the estimates are presumably due to a completely different experimental approach. Wishart (1985) compared fresh, untreated control semen with frozen, glycerolized semen that was centrifuged and washed after thawing. However, we also glycerolized, centrifuged and washed the unfrozen control semen so that only the effects of frozen versus non-frozen semen were compared. This treatment of fresh semen was not excessively detrimental when compared to results of other studies. The $81 \cdot 3 \%$ hatch of total eggs for $\mathrm{u}$-WL $+\mathrm{u}$-RIR was lower than the $90 \cdot 1 \%$ for untreated fresh semen reported by Lake et al. (1981) but higher than the $76 \%$ (fresh pooled semen) and $73 \%$ (fresh, individual male) reported by Ivanov et al. (1982).

Fertility often fluctuates due to the physiological status of the hens, management conditions and climatic conditions. Khovnir et al. (1984) reported that fertility of frozen chicken semen ranged from 59.4 to $86.8 \%$. Semen diluent, freezing, thawing, and deglycerolation procedures strongly influence fertility (Sexton, 1979) but frozen and unfrozen semen in our study was treated exactly the same, i.e. with glycerolation, redilution, centrifugation and resuspension. Also, use of individual versus pooled semen affects fertility. Ivanov et al. (1982) reported fertilities of $85 \%$ for fresh semen from individual males versus $90 \%$ for fresh pooled semen and $64 \%$ for frozen semen from individual males versus $84 \%$ for frozen pooled semen. An advantage of the heterospermic competition approach is that fertility itself has minor importance for estimating the relative fertilizing ability, since it only deals with the ratio between RIR and WL chicks. Therefore, the heterospermic competition approach is a more objective means of estimating relative fertilizing ability than is the cell concentration approach, and yet it requires fewer animals.

Sperm cells from RIR birds had a relative fertilizing ability about 1.5 times higher than that of WL birds regardless of the freezing status. Martin et al. (1974) reported that, when equal numbers of unfrozen Columbian and Leghorn spermatozoa were inseminated, the Columbian male sired $34 \%$ of the offspring. This difference in fertility between males was not due to the breed of hen used. Allen \& Champion (1955) reported that there was no difference in fertility due to breed of hen but there were differences due to \% motile and defective spermatozoa. Khovnir et al. (1984) reported that there were significant differences in fertility between breeds. The use of pooled semen, as in this study, minimizes the effects of individual males and improves the appraisal of freezing effects. However, there apparently was a difference in fertility between RIR and WL semen.

The term "relative fertilizing ability" was used by Martin \& Dziuk (1977) and Martin et al. (1974). In this report, "relative fertilizing ability" is defined as a measure for the proportion of sperm cells that are functionally fertile in a given population of sperm cells. Increasing sperm numbers may increase fertility but the relative fertilizing ability (the proportion of sperm cells that are functionally fertile) may not be changed. Therefore, fertility and relative fertilizing ability should be strictly differentiated.

In summary, the heterospermic competition method is a very powerful tool for estimating the relative fertilizing ability of spermatozoa with different physiological conditions when combined with the appropriate statistical procedures.

We thank Dr R. N. Schoffner and Mr J. S. Otis for advice and support in conducting the experiment; Mr S. E. Whiting and staff of the Poultry Teaching and Research facility of the University of Minnesota for co-operation and support; Ms R. C. Deyo and S. M. Swanson for technical assistance; and Ms L. J. Keck for typing the manuscript.

Scientific Publication No. 15950 of the Minnesota Agricultural Experimental Station, St Paul, MN 55108, USA. 


\section{References}

Allen, P.E. \& Champion, L.R. (1955) Competitive fertilization in the fowl. Poultry Sci. 34, 1332-1342.

Beatty, R.A., Bennett, G.H., Hall, J.G., Hancock, J.L. \& Stewart, D.L. (1969) An experiment with heterospermic insemination in cattle. J. Reprod. Fert. 19, 491-502.

Bishop, Y.M.M., Fienberg, S.E. \& Holland, P.W. (1975) Discrete Multivariate Analysis Theory and Practice. MIT Press, Cambridge, MA.

Burrows, W.H. \& Quinn, J.P. (1937) Collection of spermatozoa from the domestic fowl and turkey. Poultry Sci. 16, 19-24.

Fienburg, S.E. (1980) Analysis of Cross Classified Categorical Data. M.I.T. Press, Cambridge, MA.

Ivanov, B., Popov, I., Tur, B., Agapova, Z. \& Frolova, E. (982) Using deep frozen semen in flocks selected for egg production. Ptitsevodstvo 10, 27-28.

Khovnir, O.A., Ivanov, B.I., Popov, I.I. \& Tur, B.K. (1984) The use of gamete freezing for preservation of fowl genetic resources. Vop. vet. okhot. khozyaistve, Moscow, 61-64.

Lake, P.E., Ravie, O. \& McAdam, J. (1981) Preservation of fowl semen in liquid nitrogen: application to breeding programmes. Br. Poultry Sci. 22, 71-77.

Martin, P.A. \& Dziuk, P.J. (1977) The effect of storage on spermatozoa in vitro and the composition of the extender on the proportion of offspring from heterospermic insemination in the chicken. $J$. Reprod. Fert. 50, 297-300.
Martin, P.A., Reimer, T.J., Lodge, J.R. \& Dziuk, P.J. (1974) The effect of ratios and number of spermatozoa from two males on proportion of offspring. $J$. Reprod. Fert. 39, 251-258.

NAG (1986) The GLIM System Release 3.77 Manual. Numerical Algorithms Group, Oxford, England.

O'Reilly, P.J., Graves, C.N. \& Dziuk, P.J. (1972) Heterospermic insemination of rabbit semen as a means of evaluating techniques of semen handling. $J$. Reprod. Fert. 29, 49-56.

Roche, J.F., Dziuk, P.J. \& Lodge, J.R. (1968) Competition between fresh and aged spermatozoa in fertilizing rabbit eggs. J. Reprod. Fert. 16, $155-157$.

Salisbury, G.W. \& VanDemark, N.L. (1961) Physiology of Reproduction and Artificial Insemination of Cattle. W.H. Freeman and Co., San Francisco.

SAS (1985) SAS User's Guide: Statistics. Version 5 edn. SAS Institute Inc., Box 8000, Cary, NC 27511.

Sexton, T.J. (1979) Preservation of poultry semen-A review. Symp. Beltsville Symposia in Agricultural Research. 3. Animal Reproduction. Osmum and Co. Publ., Montclair, NJ.

Wishart, G.J. (1985) Quantitation of the fertilizing ability of fresh compared with frozen and thawed fowl spermatozoa. Br. Poultry Sci. 26, 375-380.

Received 2 February 1988 